\title{
Disseminated intravascular coagulation, antiphospholipid antibodies, and ischaemic necrosis of extremities
}

\author{
A G BIRD. ${ }^{1}$ R LENDRUM , ${ }^{2}$ R A ASHERSON ${ }^{3}$ AND G R V HUGHES \\ From the 'Department of Immunology, Newcastle General Hospital, Newcastle upon Tyne; the ${ }^{2}$ Medical Unit \\ No 1, Freeman Hospital, Newcastle upon Tyne; and the ${ }^{3}$ Lupus Arthritis Research Unit. The Rayne Institute, \\ St Thomas's Hospital, London
}

SUMMARY A middle aged woman presented with acute, severe, intravascular coagulation leading to ischaemic necrosis of the extremities. Pulmonary involvement required artificial ventilation, and there was evidence of hepatic, pancreatic, and renal damage, which resolved without complication. These events may have been triggered by the ingestion of compound diuretic tablets. The finding of the 'lupus anticoagulant' and anticardiolipin antibodies, together with high titre antinuclear factor in the serum, and antibodies to extractable nuclear antigen (RNP), and a past history of spontaneous abortion, suggest that this was a dramatic manifestation of an immune connective tissue disorder.

Key words: gangrene, drug induced.

\section{Case history}

A previously healthy 52 year old white woman was admitted as an emergency. She had been lethargic for three months and had recently noted pain and swelling in her hands. Three weeks before admission she had taken one combination diuretic tablet (triamterene $50 \mathrm{mg}$ and hydrochlorothiazide $25 \mathrm{mg}$ ), after which she became unwell with weakness, nausea, and vomiting for 24 hours. On the day before admission she again took the diuretic tablet and 12 hours later developed rigors, nausea, vomiting, diarrhoea, and shortness of breath. She complained of severe pains in the arms and legs. On admission she was confused and pyrexial $\left(38.5^{\circ} \mathrm{C}\right)$ with a tachycardia of $140 /$ minute. Her blood pressure was unrecordable and there was marked cyanosis of the nose, hands, and feet (Fig. 1).

Her past medical history had been unremarkable apart from the miscarriage of a twin conception 17

Accepted for publication 17 September 1986.

Correspondence to Dr A G Bird. Regional Immunology Department, Newcastle General Hospital. Westgate Road. Newcastle upon Tyne NE4 6BE. years earlier. At no time had there been evidence of arthropathy, Raynaud's phenomenon, or facial erythema.

I N VES T I G A T I O N S

Laboratory investigations on admission were as follows: haemoglobin $12.9 \mathrm{~g} / \mathrm{dl}(129 \mathrm{~g} / \mathrm{l})$; white blood cell count $17 \times 10^{9} / 1$; platelets initially $200 \times 10^{9} / 1$ falling to $80 \times 10^{9} / 1$ after one week; blood glucose $6 \cdot 3$ $\mathrm{mmol} / \mathrm{l}$; plasma sodium $134 \mathrm{mmol} / \mathrm{l}$; potassium $5 \cdot 1$ $\mathrm{mmol} / \mathrm{l}$; chloride $99 \mathrm{mmol} / \mathrm{l}$; bicarbonate $99 \mathrm{mmol} / \mathrm{l}$; urea $15.7 \mathrm{mmol} / \mathrm{l}$; creatinine $282 \mu \mathrm{mol} / \mathrm{l}$. Arterial blood gas analysis showed $\mathrm{pH} 7.56, \mathrm{Po}_{2} 9.2 \mathrm{kPa}$, $\mathrm{PCO}_{2} 2.5 \mathrm{kPa}$. Serum total protein was $54 \mathrm{~g} / \mathrm{l}$, albumin $32 \mathrm{~g} / \mathrm{l}$, calcium $2 \cdot 10 \mathrm{mmol} / \mathrm{l}$, phosphate $1.4 \mathrm{mmol} / \mathrm{l}$, bilirubin $8 \mu \mathrm{mol} / \mathrm{l}$, alkaline phosphatase $68 \mathrm{IU} / \mathrm{l}$ (normal <92 IU/l), aspartate transaminase (AST) 197 IU/l (normal <37 IU/l). Clotting studies showed a prothrombin time of 32 seconds (control 13 seconds), kaolin-cephalin time 72 seconds (normal $<40$ seconds), thrombin time 38 seconds (normal $<40$ seconds). The level of fibrin degradation products was $320 \mu \mathrm{g} / \mathrm{l}$ of serum rising to over $500 \mu \mathrm{g} / \mathrm{l}$; fibrinogen $0.7 \mathrm{~g} / \mathrm{l}$ (normal $2-4 \mathrm{~g} / \mathrm{l}$ ). Low 


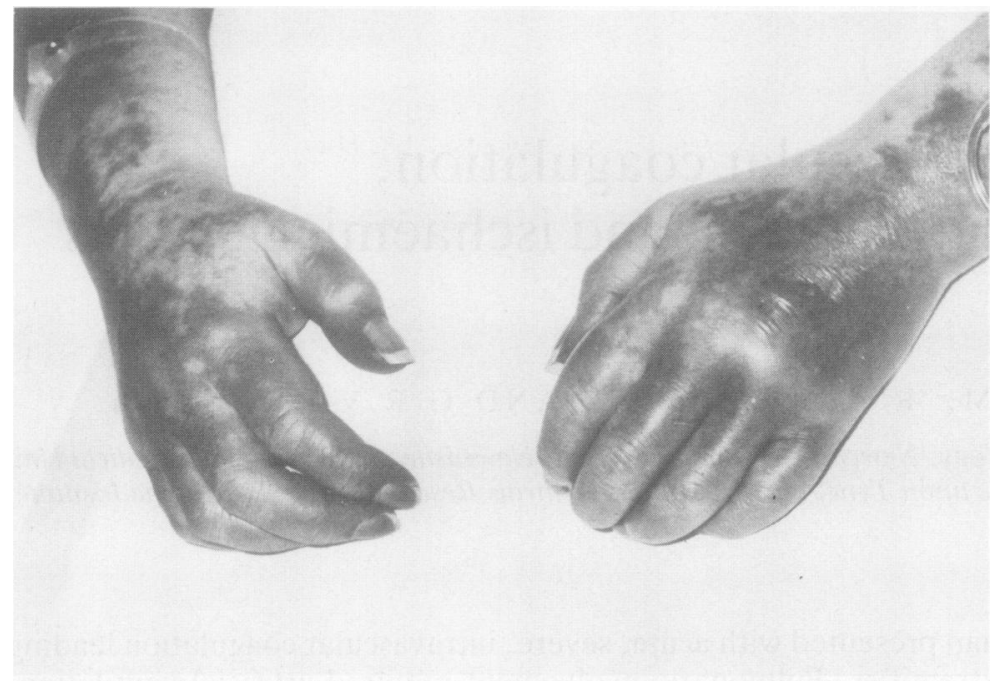

Fig. 1 Appearance of hands on second day after admission.

titre cold agglutinins were initially detected. Cryoglobulins were not present. Serum complement levels were low: $\mathrm{C} 30.68 \mathrm{~g} / \mathrm{l}$ (normal range 0.75 $1.5 \mathrm{~g} / \mathrm{l})$. C4 $0 \cdot 15 \mathrm{~g} / \mathrm{l}$ (normal range ().14-0.42 g/l).

COURSE AND MANAGEMENT

A provisional diagnosis of disseminated intravascular coagulation secondary to presumed septicaemia was made. She was treated with intravenous plasma protein fraction, blood transfusions, intravenous hydrocortisone $(100 \mathrm{mg}$, intravenously, eight hourly), $35 \%$ oxygen, and intravenous antibiotics (ampicillin $2 \mathrm{~g}$ and flucloxacillin $2 \mathrm{~g}$, six hourly; metronidazole $400 \mathrm{mg}$, eight hourly). Atrial fibrillation supervened requiring intravenous digoxin. Later that day intravenous heparin, $15000 \mathrm{IU} / 24$ hours, was added. An initial central venous pressure of $-10 \mathrm{~cm}$ was improved to $+4 \mathrm{~cm}$. Basal lung crepitations developed and the chest $x$ ray showed diffuse alveolar shadowing.

Twelve hours after admission her blood pressure had risen to $110 / 80 \mathrm{mmHg}$, with a pulse rate of $140 /$ minute, sinus rhythm. Her confusion improved and she now responded to questions. There was no abdominal pain or tenderness, but bowel sounds were absent and small bowel fluid levels were visible on plain $x$ ray. Peripheral pulses were all easily palpable and the $\mathrm{PCO}_{2}$ had risen to $13.8 \mathrm{kPa}$; the cyanosis of the extremities had, however, become more pronounced. Urine output was satisfactory at $50-100 \mathrm{ml} / \mathrm{h}$.

The following morning she complained of worsening pains in the hands and feet. She was febrile, $38^{\circ} \mathrm{C}$, the respiratory rate had risen to $50 /$ minute, and the blood pressure had fallen to $80 \mathrm{mmHg} \overrightarrow{0}$ systolic with a pulse of $130 /$ minute and central $\underset{v}{ }$ venous pressure $+1 \mathrm{~cm}$. Chest $x$ ray again showed $\square$ alveolar shadowing and blood gas analysis had deteriorated ( $\left.\mathrm{pH} 7 \cdot 35 ; \mathrm{Po}_{2} 6.6 \mathrm{kPa} ; \mathrm{PCO}_{2} 4.2 \mathrm{kPa}\right)$. There was tenderness in the epigastrium; serumo amylase was 510 IU/l. She was transferred to theㅁ intensive care unit (Dr D W Ryan) for intermittent positive pressure ventilation. Abdominal ultrasound음 showed no evidence of hepatic or intra-abdominal abscess. Bowel ischaemia seemed likely.

No evidence of bacterial infection was found oninitial blood and urine cultures or high vaginal swab. ొొ Subsequently the results of tests for hepatitis B. mycoplasma, legionella, and virus titres were nega-3. tive. The antibiotics were changed to intravenous metronidazole $400 \mathrm{mg}$ and erythromycin $1 \mathrm{~g}$, eight hourly. Intravenous dextran 40 and glyceryl trini-o trate were given in addition to heparin to try to improve the peripheral circulation. The distal hands feet, and nose now appeared frankly gangrenous.

The serum AST level rose to a maximum of $900 \mathrm{~N}$ IU/l on the second day. Her fever resolved and $N$ artificial ventilation was discontinued five days after admission; bowel sounds returned the next day. The serum amylase continued to rise to a maximum of $2543 \mathrm{IU} / \mathrm{l}$ on the seventh day. The serum albumin had fallen to $26 \mathrm{~g} / \mathrm{l}$ and marked oedema of the lower $\overline{\mathscr{D}}$ limbs and sacrum developed. The chest $x$ ray and renal function rapidly returned to normal.

Antibiotics were discontinued after 12 days. Treatment was simplified to oral prednisolone $60 \mathrm{mg} \frac{\widehat{P}}{\mathrm{D}}$ daily, potassium supplements, and buprenorphine for pain in the limbs. There was by now well 
demarcated ischaemic necrosis of the distal hands, feet, and nose (Figs 2 and 3).

During the ensuing two months she underwent a

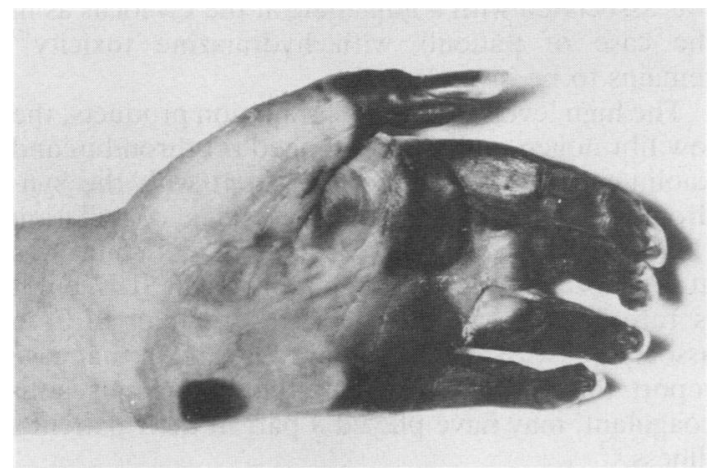

Fig. 2 Left hand one month after admission. (The appearance of the right hand was very similar.)

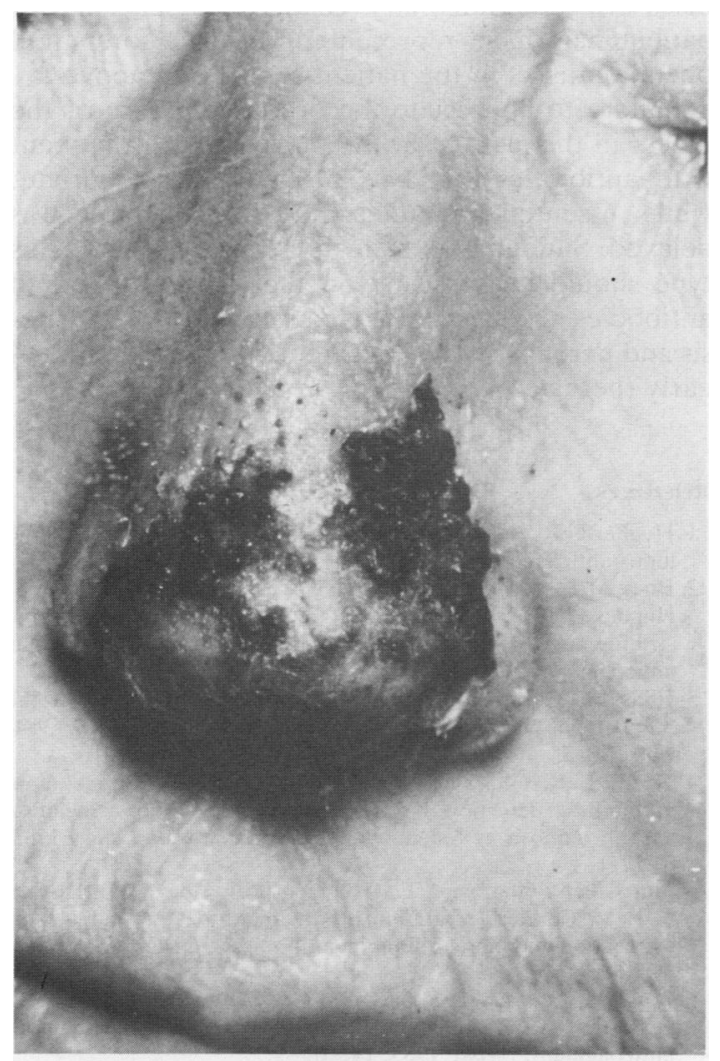

Fig. 3 Nose one month after admission. series of plastic surgical procedures to treat the ischaemic limbs (Mr M J M Black). Serial amputations of the left fingers and thumb. distal amputation of both feet, amputation of the right fingers and thumb, and skin grafting to the left hand were carried out. Three months after admission she was able to walk with the help of two physiotherapists and all operation sites were healing well. The nose healed without surgical intervention. She was now being treated with oral prednisolone $35 \mathrm{mg}$ daily. and azathioprine $100 \mathrm{mg}$ daily was added. Four months after the onset of the illness painful peripheral paraesthesiae developed, and nerve conduction studies confirmed motor and sensory peripheral neuropathy. A course of cyclophosphamide $150 \mathrm{mg}$ daily was commenced instead of azathioprine. Six weeks later she developed troublesome urinary frequency. This was attributed to the cyclophosphamide, which was therefore stopped and replaced by azathioprine $150 \mathrm{mg}$ daily. During the following 12 months this immunosuppressive treatment was gradually reduced to a maintenance dose of prednisolone $5 \mathrm{mg}$ and azathioprine $25 \mathrm{mg}$ orally daily. Her general health was now excellent and there had been a gradual improvement in the paraesthesiae. Full blood count, platelets, erythrocyte sedimentation rate, liver function tests, blood urea, electrolytes, and serum amylase have remained consistently normal.

IMMUNOLOGICAL' TESTS

After recovery from the initial illness serum immunoglobulins were normal $(\operatorname{IgM} 1.7 \mathrm{~g} / 1 ; \operatorname{IgG} 9.7 \mathrm{~g} / \mathrm{l}$; IgA $1 \cdot 0 \mathrm{~g} / \mathrm{l})$. Serum complement estimation showed a normal C3 $(1.02 \mathrm{~g} / \mathrm{l})$, reduced $\mathrm{C} 4(0 \cdot 13 \mathrm{~g} / \mathrm{l})$, and low $\mathrm{CH}_{50}$ (1200 units $/ \mathrm{ml}$, normal 1260-2880 units $/ \mathrm{ml}$ ). $\mathrm{IgG}$ antinuclear factor was present at a titre of 1/1280; antibodies to extractable nuclear antigens (anti-RNP) were found in a titre of $1 / 4$. The DNA binding was consistently negative. Both IgM and IgG anticardiolipin antibodies were detected in high titre.

A forearm skin biopsy one month after admission showed generalised dermal atrophy with mild perivascular lymphocytic infiltrates. Direct immunofluorescence showed granular C3 and IgM deposition in dermal capillaries and small arterioles, consistent with small vessel vasculitis. No IgM. IgG. or C3 deposits were demonstrable at the dermoepidermal junction: thus the 'lupus band' typically found in established systemic lupus erythematosus (SLE) was not present. Sixteen months after the presenting illness both IgM and IgG anticardiolipin binding assays had become negative; antinuclear factor remained positive, titre $1 / 40$; serum levels of $\mathrm{C} 3$ and $\mathrm{C} 4$ were now within the normal range. 


\section{Discussion}

This patient became acutely and severely ill a short time after the ingestion of a compound diuretic tablet. During the early stages of this illness she was seen by several physicians and surgeons, none of whom had seen a similar presentation previously. She was thought to have an overwhelming septicaemia, or septic shock syndrome, or an acute drug induced vasculitis. The treatment given was therefore empirical and non-specific. The 'lupus anticoagulant' or anticardiolipin antibody tests were not locally available at that time and the positive result became known only after she had recovered. In retrospect the history of abortion, the precipitation of illness by drugs, the vascular occlusion, and the immunological findings suggest that this may have been a further example of the protean presentations of antiphospholipid antibodies. ${ }^{1}$

Although antiphospholipid antibodies ('lupus anticoagulant', anticardiolipin antibodies, false positive Venereal Disease Research Laboratory (VDRL) test) have been most frequently associated with venous occlusions, ${ }^{2-4}$ arterial thrombosis has also been reported with increasing frequency. Occlusion of large cerebral vessels resulting in stroke is not uncommon in SLE,,${ }^{56}$ and involvement of other arteries such as mesenteric, ${ }^{78}$ retinal, ${ }^{9}$ and coronary $^{10}$ has also been recorded. Large vessel arterial involvement with gangrene of the extremities has recently been described. ${ }^{11} 12$ Although most of the patients reported were diagnosed as having SLE according to the American Rheumatism Association criteria, ${ }^{13}$ it is now clear that many do not conform to these criteria. ${ }^{14}$ Such patients have been described as having 'lupus-like' disease, 'variant lupus', or simply 'autoimmune disorders' or 'the antiphospholipid syndrome'. Presenting features include venous or arterial occlusions, fetal loss, ${ }^{15}$ thrombocytopenia, false positive VDRL test, and less frequently pulmonary hypertension ${ }^{16}$ and chorea. ${ }^{17}$ It seems possible that the fetal loss incurred by our patient 17 years earlier may also have been related to the presence of anticardiolipin antibodies.

The association of antiphospholipid antibodies with drug therapy has also been recorded. Mueh et al in 1980 described eight patients with psychiatric illness treated with phenothiazines, who demonstrated the 'lupus anticoagulant', and thrombotic events (thrombophlebitis, pulmonary embolus, cerebral thrombosis) occurred in three of these. ${ }^{18}$ Hydralazine had been administered in two others and procainamide in one. All of these compounds have been associated with the development of a drug induced 'lupus syndrome'. The development of symptoms in our patient on two occasions aftew. diuretic administration suggests that the sever illness reported here may also have been drus induced. Whether the low $\mathrm{C} 4$ level in this patien was associated with a null allele at the $\mathrm{C} 4$ locus as i the case of patients with hydralazine toxicity $\frac{\mathbf{v}^{9}}{2}$ remains to be investigated.

The high levels of fibrin degradation products, th low fibrinogen, and the prolonged prothrombin and kaolin-cephalin times are consistent with the syn drome of disseminated intravascular coagulation (DIC) in our patient, though the platelet count was at first normal. DIC has been reported in SLE, but f $_{0}$ is rare. ${ }^{2021}$ It has also been recorded in SLE in association with acute pneumonitis, and in that case report the authors comment that the 'lupus antio coagulant' may have played a part in their patient $\$$ illness. ${ }^{22}$

Although our patient did not have diagnosable SLE, she manifested a high antinuclear antibod and precipitating antibodies to nRNP. She had nơ clinical features suggestive of any other connective tissue disease, such as mixed connective tissu $\overrightarrow{\mathrm{B}}$ disease. The pulmonary changes present in oup patient may have represented an acute interstitiat pneumonitis as in the patient referred to above. ${ }^{22}$

Failure to appreciate the probable nature of the illness in this patient at the outset led to treatmeat with antibiotics that was probably inappropriate while essential immunosuppressive therapy was? delayed. Sudden unexplained vascular events of the type should cause suspicion that antiphospholip? antibodies may be present, leading to earlier diagnof sis and perhaps to the development of more rational early therapy.

\section{References}

1 Hughes G R V. Thrombosis, abortion, cerebral disease and th lupus anticoagulant. $\mathrm{Br}$ Med $J$ 1983; 287: 1088-9.

2 Bocy M L. Colaco C B, Gharavi A E, Elkon K B, Loizou $\$$ Hughes G R V. Thrombosis in systemic lupus erythematosus: striking association with the presence of circulating lup anticoagulant. $\mathrm{Br}$ Med $J$ 1983; 287: 1021-3.

3 Elias M. Eldor A. Thromboembolism in patients with tor 'lupus-type' circulating anticoagulant. Arch Intern Med 1984; 144: $510-5$.

4 Harris E N, Gharavi A E, Boey M L. et al. Anticardiolipể antibodies: detection by radioimmunoassay and associatief with thrombosis in systemic lupus erythematosus. Lancet 1983 ; ii: $1211-4$.

을

5 Harris E N, Gharavi A E, Asherson R A. Boey M L. Hugh G R V. Cerebral infarction in systemic lupus erythematos association with anticardiolipin antibodies. Clin Exp Rheumatel 1984; $2: 47-51$.

6 Landi G, Calloni V. Sabbadini M G, Mannucci P, Candelise Recurrent ischacmic attacks in two young adults with lupus anticoagulant. Stroke 1983; 14: 377-9.

7 Asherson R A. Mackworth-Young C G, Harris E N, Gharâti A E. Hughes G R V. Multiple venous and arterial occlusieg 
associated with the lupus anticoagulant and antibodies to cardiolipin in the absence of SLE. Rheumatol Int 1985; 5: 91-3.

8 Asherson R A, Morgan S H, Harris E N, Gharavi A E, Hughes G R V. Arterial occlusion causing large bowel infarction - a reflection of clotting diathesis in SLE. Clin Rheumatol 1985: 5: 102-6.

9 Hall S, Buettner H, Luthra H S. Occlusive retinal vascular disease in systemic lupus erythematosus. $J$ Rheumatol 1984; 11 : 846-50.

10 Asherson R A, Mackay I R, Harris E N. Myocardial infarction in a young male with systemic lupus erythematosus, dcep vein thrombosis and antiphospholipid antibodies. Br Heart J 1986; 56: $190-3$.

11 Jindal S K, Martin M F R, Gayner A. Gangrenc developing after minor surgery in a patient with undiagnosed systemic lupus erythematosus and 'lupus anticoagulant'. Ann Rheum Dis 1983; 42: 347-9.

12 Asherson R A, Derksen R H W M, Harris E N, Gharavi A E, Kater L, Hughes G R V. Large vessel occlusion and gangrene in systemic lupus erythematosus and 'lupus-like' disease. A report of six cases. J Rheumatol 1986; 13: 740-7.

13 Tan E M, Cohen A S, Fries J F, et al. The 1982 revised criteria for the classification of SLE. Arthritis Rheum 1982; 25: 1271-7.

14 Asherson R A, Chan J K H, Harris E N, Gharavi A E, Hughes G R V. Clinical and laboratory features associated with anticardiolipin antibodies in non-SLE paticnts. Arthritis Rheum 1985: 28 (suppl): S77.

15 Firkin B G. Howard M A. Radford N. Possible relationship between the lupus inhibitor and recurrent abortion in young women. Lancet 1980; ii: 366.

16 Asherson R A. Mackworth-Young C G, Bocy M L, et al. Pulmonary hypertension in systemic lupus erythematosus. $\mathrm{Br}$ Med J 1983: 287: 1024-5.

17 Asherson R A, Derksen R H W M, Bouma B N, et al. Chorea in systemic lupus erythematosus and 'lupus-like' disease. Association with antiphospholipid antibodies. Semin Arthritis Rheum (in press).

18 Mueh J R, Herbst K D, Rapaport S I. Thrombosis in patients with the lupus anticoagulant. Ann Intern Med 1950; 92: 156-9.

19 Batchelor J R, Welsh K I, Tinoco R M. et al. Hydralazineinduced systemic lupus erythematosus: the influence of HLADR and sex upon susceptibility. Lancet 1980; i: 1107-9.

20 Beall C L. Pierce L E. Intravascular coagulation in acutc lupus erythematosus. JAMA 1975; 234: 518-9.

21 McKay D G. Disease of hypersensitivity - disseminated intravascular coagulation. Arch Intern Med 1965; 116: 83-94.

22 Chellingsworth M, Scott D G I. Acute systemic lupus erythematosus with fatal pneumonitis and disseminated intravascular coagulation. Ann Rheum Dis 1985; 44: 67-9. 